\title{
Imaging of Phospholipids in Formalin Fixed Rat Brain Sections by Matrix Assisted Laser Desorption/lonization Mass Spectrometry
}

\author{
Claire L. Carter, ${ }^{1}$ Cameron W. McLeod, ${ }^{2}$ Josephine Bunch ${ }^{1}$ \\ ${ }^{1}$ The School of Chemistry, University of Birmingham, Edgbaston, Birmingham, B15 2TT, UK \\ ${ }^{2}$ The Centre for Analytical Sciences, Department of Chemistry, Brookhill, University of Sheffield, Sheffield, S3 7HF, UK
}

\begin{abstract}
Matrix-assisted laser desorption/ionization mass spectrometry (MALDI-MS) is a valuable tool for the analysis of molecules directly from tissue. Imaging of phospholipids is gaining widespread interest, particularly as these lipids have been implicated in a variety of pathologic processes. Formalin fixation (FF) is the standard protocol used in histology laboratories worldwide to preserve tissue for analysis, in order to aid in the diagnosis and prognosis of diseases. This study assesses MALDI imaging of phospholipids directly in formalin fixed tissue, with a view to future analysis of archival tissue. This investigation proves the viability of MALDI-MSI for studying the distribution of lipids directly in formalin fixed tissue, without any pretreatment protocols. High quality molecular images for several phosphatidylcholine (PC) and sphingomyelin (SM) species are presented. Images correspond well with previously published data for the analysis of lipids directly from freshly prepared tissue. Different ionization pathways are observed when analyzing fixed tissue compared with fresh, and this change was found to be associated with formalin buffers employed in fixation protocols. The ability to analyze lipids directly from formalin fixed tissue opens up new doors in the investigation of disease profiles. Pathologic specimens taken for histologic investigation can be analyzed by MALDI-MS to provide greater information on the involvement of lipids in diseased tissue.
\end{abstract}

Key words: MALDI-MS, Mass spectrometry imaging, Phospholipids, Formalin fixed tissue, Ionisation pathways

\section{Introduction}

$\mathrm{M}$ atrix-assisted laser desorption/ionization mass spectrometric imaging (MALDI-MSI) was introduced in 1997 [1] and has been widely presented as a powerful method for imaging large [2-14] and small molecules [15$24]$ in tissue. The technique has been applied to a diverse range of applications but there has been particular interest in evaluating opportunities in disease state profiling. MALDIMSI has been successfully used to identify disease biomarkers $[2,9,25]$ and to aid in the diagnosis and prognosis of carcinomas [2, 9, 11, 25, 26].

Correspondence to: Josephine Bunch; e-mail: j.bunch@bham.ac.uk
Traditional analysis of pathologic specimens employs histologic staining procedures to investigate tissue anatomy $[27,28]$. Labeled antibodies are often used in conjunction with staining protocols for the visualization of specific biomarkers that aid in the diagnosis and prognosis of diseases; this is a subset of histology known as immunohistochemistry (IHC) [27-30]. IHC, as with other molecular labeling methods, is often limited in its ability to yield information on multiple species in a single section. Mass spectrometry imaging offers simultaneous label free analysis of multiple species in a single experiment, providing significant insights into disease pathogenesis $[4,5,7,9,12-14,31-34]$.

Conventional methods for collection and storage of tissue for histologic evaluation uses formalin fixation to chemically 
preserve the tissue by preventing proteolytic degradation [35]. Formalin fixation (FF) causes inter- and intra-crosslinking between proteins and proteins and nucleic acids, which presents issues for direct analysis of proteins by IHC and mass spectrometry [36-38]. This crosslinking is thought to predominantly involve hydroxymethylene bridges, but it has also been suggested that formation of coordinate bonds for calcium ions may play a role [39]. The net result is the masking of epitopes (antibody binding sites). There are several techniques for reversing this crosslinking, to 'unmask' these epitopes, which are widely used in IHC and referred to as antigen retrieval 'methods'. These methods involve enzymatic digestion, protein denaturation, heat treatment and heat-induced antigen retrieval (HIAR) $[37,39,40]$.

Investigators attempting to analyze proteins in fixed tissue via MALDI-MSI have explored the use of enzymatic digestion prior to analysis $[38,41-43]$. Research has also involved development of MALDI compatible staining protocols [44] as well as performing MALDI prior to histologic staining [45]. These studies have aimed to establish methods that would permit direct comparison and correlation of images from microscopy and mass spectrometry. Compatible protocols would facilitate full correlation of spectral data with areas of interest highlighted in high resolution microscopy and enable analysis of proteins in archival material by MALDI.

There has been increasing interest in the field of lipidomics, which has led to significant research into the analysis and imaging of lipids in tissue sections by MALDIMS [16, 20, 24, 25, 31, 34, 46-59]. There is now considerable evidence that lipids are differentially expressed in normal and diseased tissue, and that they may play a central role in the pathologic processes associated with numerous disease states, including diabetes, Alzheimer's and dementia, cancer, heart disease, and numerous metabolic diseases [25, 50, 52, 58, 60-69].

Analysis and imaging of formalin fixed tissue sections would improve correlation of MS lipid data with histologic findings and permit MALDI analysis of sections prepared from organs stored in formalin. Lipid profiles have been investigated from formalin fixed bovine lens tissue [70], but imaging of phospholipids directly from formalin fixed tissue sections has not been presented.

This study was designed to assess the effects of formalin fixation on analysis and imaging of phospholipids in thin tissue sections. Phospholipids are the most abundant lipid constituents, are widely distributed in the brain, and are readily ionized and detected in MALDI MS experiments. Several studies have already reported the distribution of the commonly known phospholipids within the anatomical regions of the brain in fresh tissue sections $[16,20,22,24,46,47,51,54-56,71-73]$. Results from these studies provide a useful basis for the assessment of new sample preparation methods for MALDI-MSI.
We present an evaluation of imaging phospholipids in fixed tissue by MALDI-MS. MS images and spectral data obtained from analysis of formalin fixed tissue are compared directly with data from fresh tissue. The effects of formalin fixation are considered with respect to image quality, sensitivity, and the localization of selected species. Studies were also conducted to assess the differences in salt adduct formation of lipid species ionized from fresh and fixed tissue.

\section{Experimental}

\section{Materials}

$\alpha$-Cyano-4-hydroxy cinnamic acid ( $\alpha$-CHCA) and trifluoracetic acid (TFA) were purchased from SigmaAldrich (Dorset, UK); 10\% neutral buffered formalin (NBF) was supplied by the Histology Department of the Medical School at the Royal Hallamshire Hospital, (Sheffield, UK); methanol was purchased from Fisher Scientific (Loughborough, UK); whole control rat brains were supplied by Covance, (Harrogate, UK); a TM Sprayer (automated matrix deposition system) was supplied by Leap Technologies, Inc. (Carrboro, NC, USA).

\section{Tissue Preparation for MALDI MSI of Phospholipids}

A whole rat brain was removed from the $-80{ }^{\circ} \mathrm{C}$ freezer and allowed to thaw at room temperature. Once thawed, the brain was placed in $10 \% \mathrm{NBF}$ and fixed for $72 \mathrm{~h}$. Fixed and fresh brains were bisected and half of each was mounted onto a cryostat chuck, using water-ice slush. Twelve $\mu \mathrm{m}$ serial sections of each brain were thaw-mounted onto stainless steel MALDI target plates for mass spectrometry and glass slides for histology. Tissue samples were coated in $5 \mathrm{mg} \mathrm{mL}{ }^{-1} \alpha \mathrm{CHCA}$ matrix material, prepared in $80 \%$ methanol $(0.1 \%$ TFA $)$ using the Leap TM sprayer. Plates were sprayed at $150{ }^{\circ} \mathrm{C}, 10 \mathrm{psi}$, a flow rate of $0.25 \mathrm{~mL} / \mathrm{min}$ with a stage velocity of $500 \mathrm{~mm} / \mathrm{min}$. Each target insert was sprayed with eight cycles.

\section{Tissue Preparation for MALDI-MSI of Formalin Spiked Tissue Samples}

Twelve $\mu \mathrm{m}$ serial sections of fresh brain were prepared as above and subsequently spiked with $0.1 \mu \mathrm{L}$ of formalin in nine locations. Approximately $9 \mathrm{~mL}$ of a $25 \mathrm{mg} \mathrm{mL}^{-1} \alpha-$ CHCA solution, (prepared in $80 \%$ methanol $(0.1 \%$ TFA) was deposited over each plate in repeated cycles via airspray deposition (Badger Airbrush, Shesto Ltd., London, UK).

\section{Mass Spectrometry}

All experiments were carried out on a QqTOF (Qstar Elite) mass spectrometer (Applied Biosystems, Foster City, CA, USA), operated in positive ion reflectron mode. Instrument parameters had been previously optimised for the analysis of 
PCs from rat brain. The Nd:YAG $(355 \mathrm{~nm})$ laser was operated at $20 \%$ available power $(2.1 \mu \mathrm{J})$ with a repetition rate of $500 \mathrm{~Hz}$. The target plate stepping distance was set to $100 \mu \mathrm{m}$ for both the $\mathrm{x}$ and $\mathrm{y}$ dimension using the imaging acquisition software. Data were acquired using the 'dynamic pixel' setting, which involves the laser being moved within the $100 \mu \mathrm{m}^{2}$ pixel area and resultant data being summed to give an accumulated mass spectrum over $1 \mathrm{~s}$ for each pixel area. The resulting twodimensional ion intensity maps were generated using TissueView or oMALDI 5.1 software (supplied by MDS Analytical Technologies, Ontario, Canada).

\section{Results and Discussion}

\section{MALDI-MSI of Formalin Fixed Rat Brain Sections}

Analysis of formalin fixed rat brain sections yielded high quality molecular images for several phosphatidylcholine (PC) and sphingomyelin (SM) species. MALDI-MS images of selected lipid species clearly highlight the specific anatomical regions of the brain, as illustrated by comparing the labeled H\&E stained section in Figure 1 with MALDIMS images (Figure 1).
For example, PC $36: 4, m / z$ 804, is highly localized within the hippocampus, as shown by the ion intensity within this region. Lower ion counts for this species are observed in the cerebral cortex, striatum, and molecular/granular layer of the cerebellum. The corpus callosum, thalamus, midbrain, pons, and medulla regions are outlined by very low or zero intensity regions. Conversely PC 38:/40:4 ( $\mathrm{m} / \mathrm{z} 838)$, was not detected or displayed very low counts in the hippocampus, molecular and granular layers of the cerebellum, cerebral cortex, and striatum regions (grey matter regions). High ion counts for this lipid were observed within the corpus callosum, optic chiasm, and arbour vitae area of the cerebellum (white matter regions of the brain). Review of these images highlights the different roles lipids play within the specific anatomical regions of the brain.

The lipid images presented in Figure 1, from formalin fixed tissue, correspond well with previously published data $[16,20,22,24,46,47,51,54-56,71-74]$ and unpublished data obtained in this laboratory, for the analysis of lipid species directly from fresh rat brain sections. The three most commonly imaged lipid species within the rat brain to date, PC 34:1, PC 32:0, and PC 36:1, all display similar distributions to data published by Wang and co-workers
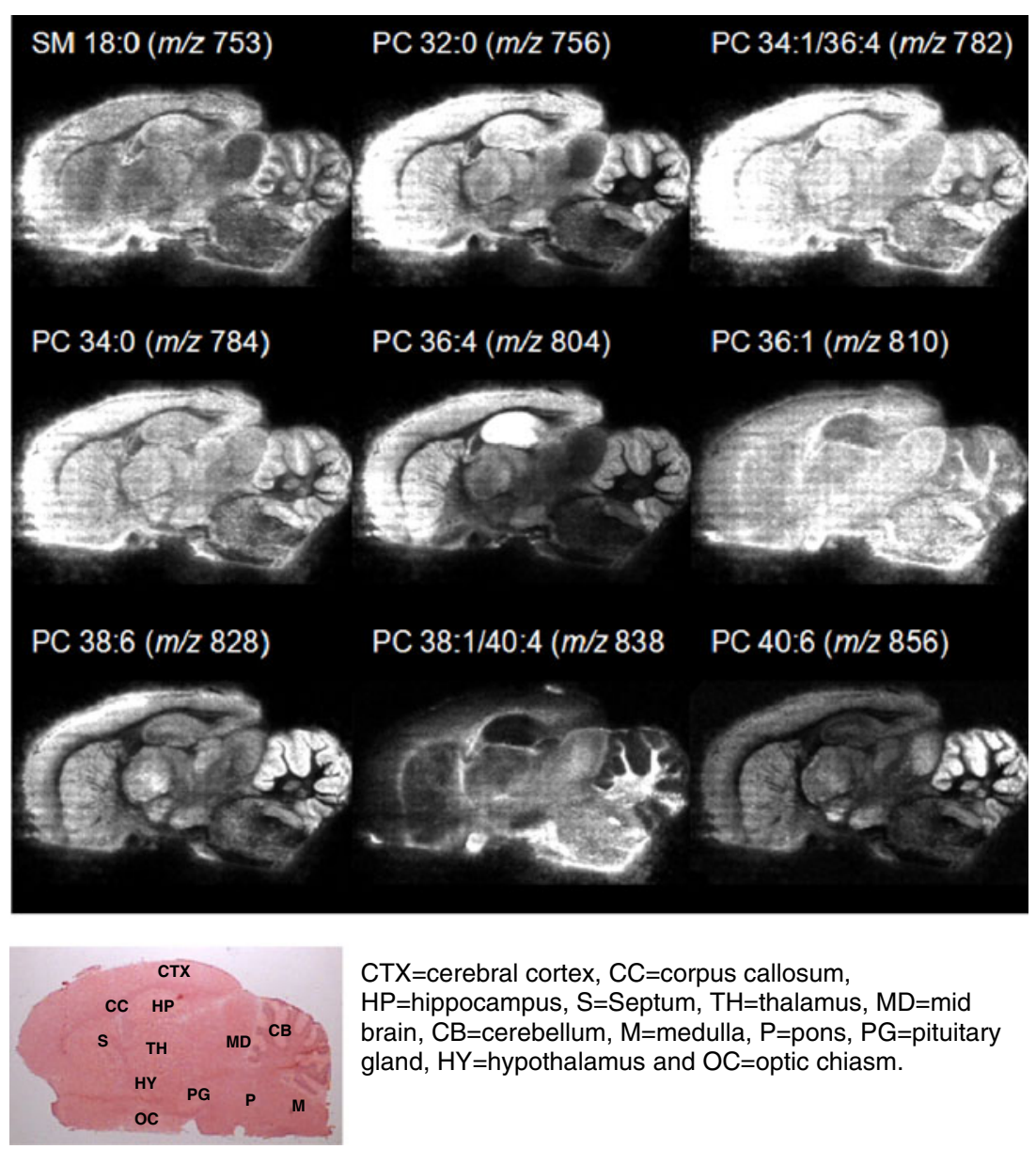

CTX=cerebral cortex,$C C=$ corpus callosum, $\mathrm{HP}=$ hippocampus, $\mathrm{S}=$ Septum, $\mathrm{TH}=$ thalamus, $\mathrm{MD}=$ mid brain, $\mathrm{CB}=$ cerebellum, $\mathrm{M}=$ medulla, $\mathrm{P}=$ pons, $\mathrm{PG}=$ pituitary gland, $\mathrm{HY}=$ hypothalamus and $\mathrm{OC}=$ optic chiasm.

Figure 1. MALDI-MS images of PC and SM species from formalin fixed sagittal rat brain sections with a haematoxylin and eosin (H\&E) stained sagittal section. Regions of anatomical interest are labeled. Image intensity ranges from 500 to 10,000 
(2008) [24]. The MALDI image of $m / z 760$ [PC 34:1+H] shows an omnipresent distribution in the brain (data not shown), however, images of $\mathrm{m} / \mathrm{z} 782$ and 798, which represent the sodium and potassium adduct, respectively, show decreased ion counts within the corpus callosum and arbour vitae region of the cerebellum. These results indicate that multiple species are detected within this spectral region. Similar results for freshly prepared sagittal sections have been obtained within our laboratory. The sodium adduct for PC 34:1, $\mathrm{m} / z 782$ shares the same $\mathrm{m} / \mathrm{z}$ as the protonated species of PC 36:4 and with the growing number of lipid species being identified it is highly possible that numerous other lipid species share this mass range.

The image of PC 32:0 ( $\mathrm{m} / \mathrm{z} 756)$ displays high ion counts outlining the grey matter regions of the brain. This is one of the most predominant PC species ionized in positive ion mode, and all adducts of this lipid share the same lateral distribution. In contrast to Wang et al (2008) [24], data presented here for the distribution of PC $36: 1 \quad(\mathrm{~m} / \mathrm{z} 810)$ shows this lipid is not confined mainly within white matter regions of the brain. An even distribution of PC 36:1 across most areas of the brain is presented in Figure 1, but lower intensity counts are seen within the hippocampus and the cerebellar cortex. It should be noted that this study used sagittal rat brain sections whereas Wang and co-workers (2008) [24] analyzed coronal sections. In addition, we have employed a different matrix system, which may account for

Table 1. Lipid Species Detected in both Fresh and Fixed Tissue with their Respective $m / z$ Values

\begin{tabular}{|c|c|}
\hline \multicolumn{2}{|c|}{ Peak assignments for fixed and fresh tissue } \\
\hline$m / z$ & Assignment \\
\hline 725.50 & $\mathrm{SM} 16: 0+\mathrm{Na}$ \\
\hline 734.57 & PC 32:0+H \\
\hline 741.50 & SM 16:0+K \\
\hline 753.50 & $\mathrm{SM} 18: 0+\mathrm{Na}$ \\
\hline 754.58 & PC $32: 1+\mathrm{Na}$ \\
\hline 760.59 & PC $34: 1+\mathrm{H}$ \\
\hline 769.50 & SM 18:0+K \\
\hline 770.57 & PC $32: 1+\mathrm{K}$ \\
\hline 781.60 & $\mathrm{SM} 20: 0+\mathrm{Na}$ \\
\hline 782.56 & PC $34: 1+\mathrm{Na}$ \\
\hline 784.57 & $\mathrm{PC} 34: 0+\mathrm{Na}$ \\
\hline 786.58 & PC $36: 2+\mathrm{H}$ \\
\hline 788.61 & PC $36: 1+H$ \\
\hline 798.55 & PC $34: 1+\mathrm{K}$ \\
\hline 800.55 & PC $34: 0+K$ \\
\hline 804.55 & $\mathrm{PC} 36: 4+\mathrm{Na}$ \\
\hline 808.59 & PC $36: 2+\mathrm{Na}$ \\
\hline 810.60 & PC $36: 1+\mathrm{Na}$ \\
\hline 820.54 & PC $36: 4+K$ \\
\hline 824.62 & PC $36: 2+\mathrm{K}$ \\
\hline 826.58 & PC $36: 1+K$ \\
\hline 828.56 & PC $38: 6+\mathrm{Na}$ \\
\hline 832.61 & PC $38: 4+\mathrm{Na}$ \\
\hline 835.60 & $\mathrm{SM} 24: 1+\mathrm{Na}$ \\
\hline 838.63 & PC $38: 1+\mathrm{Na}$ \\
\hline 844.52 & PC $38: 6+\mathrm{K}$ \\
\hline 848.60 & PC $38: 4+\mathrm{K}$ \\
\hline 851.60 & SM $24: 1+K$ \\
\hline 856.58 & $\mathrm{PC} 40: 6+\mathrm{Na}$ \\
\hline
\end{tabular}

the differences seen. The sodium adduct for PC $36: 1$ is detected at the same $\mathrm{m} / \mathrm{z}$ as the protonated species of PC 38:4. The occurrence of overlapping species in the spectral region of interest highlights that care must be taken in the interpretation of MS images.

The images presented show some evidence of laser 'oversampling' [75], which results in areas of lower ion intensity, in a geometric arrangement across the image area. This is often seen in high resolution MALDI-MS images.

A list of the lipid species ionized from both fixed and fresh tissue preparation is shown in Table 1 .
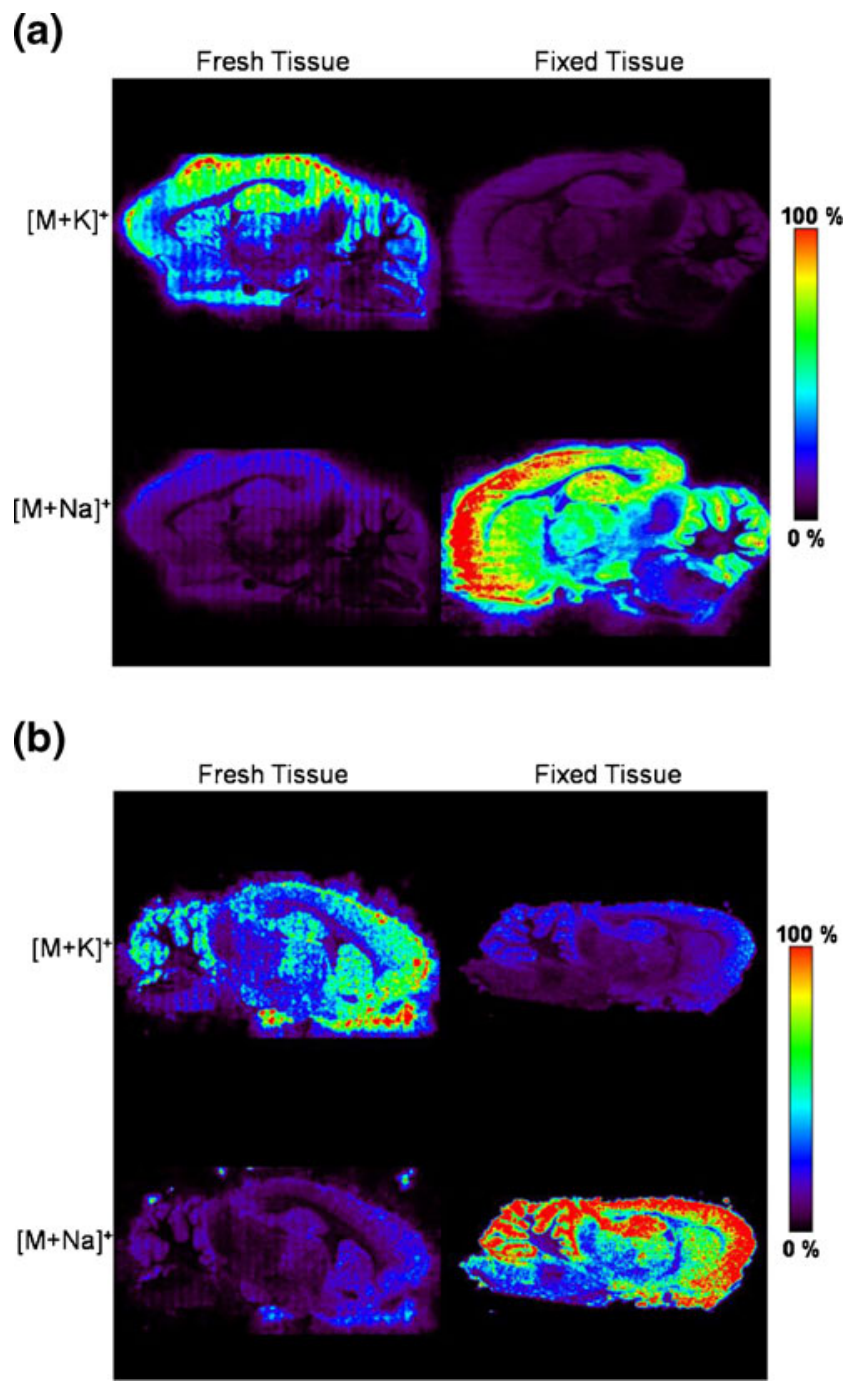

Figure 2. (a) MALDI-MS images of PC 32:0 in sagittal rat brains sections of fixed and fresh tissue, for the automated matrix deposition method. Images on the left represent the $[\mathrm{M}+\mathrm{K}]^{+}$against the $[\mathrm{M}+\mathrm{Na}]^{+}$in fresh sections, whilst images on the right represent the $[\mathrm{M}+\mathrm{K}]^{+}$against the $[\mathrm{M}+\mathrm{Na}]^{+}$in fixed sections. (b) MALDI-MS images of PC $32: 0$ in sagittal rat brains sections of fixed and fresh tissue, for the manual airbrush matrix deposition method. Images on the left represent the $[\mathrm{M}+\mathrm{K}]^{+}$ against the $[\mathrm{M}+\mathrm{Na}]^{+}$in fresh sections, whilst images on the right represent the $[\mathrm{M}+\mathrm{K}]^{+}$against the $[\mathrm{M}+\mathrm{Na}]^{+}$in fixed sections 
The images presented in Figure 2a along with spectral examination of these samples (Figure 3) revealed different ionization pathways are favoured with FF tissue compared with fresh. The sodium adduct is the most abundant species in the former compared with the potassium adduct in the latter. This was observed for all lipids that have previously been reported by MALDI-MSI. To evaluate whether this change in ionization pathway was attributed to the automated matrix deposition method (Leap TM Sprayer), the investigation was repeated using an artistic airbrush. A far superior image resolution was achieved with the automated method compared with the airbrush, as evidenced by comparing image quality in images presented in Figures 1 and 2a. The ion formation of each lipid surveyed was found to be the same between the two methods (Figure 2a and b) and so this is not thought to be related to the matrix deposition. There are also clear differences in the spectra obtained for the fixed and the fresh sections, as demonstrated by the spectral overlay presented in Figure 3. The $[\mathrm{M}+\mathrm{Na}]^{+}$is the most abundant ion in fixed tissue as shown by the red peaks in the spectra, whereas the $[\mathrm{M}+\mathrm{K}]^{+}$ion is the predominant in fresh tissue as shown by the blue peaks in the spectra. The mass shift of 16 mass units $(\mathrm{u})$ is clearly visible for each lipid species detected, particularly in the enlarged spectral region, in which the $[\mathrm{M}+\mathrm{Na}]^{+}$and $[\mathrm{M}+\mathrm{K}]^{+}$adducts of PC $32: 0$ and PC34:1 are labeled. This was further investigated by
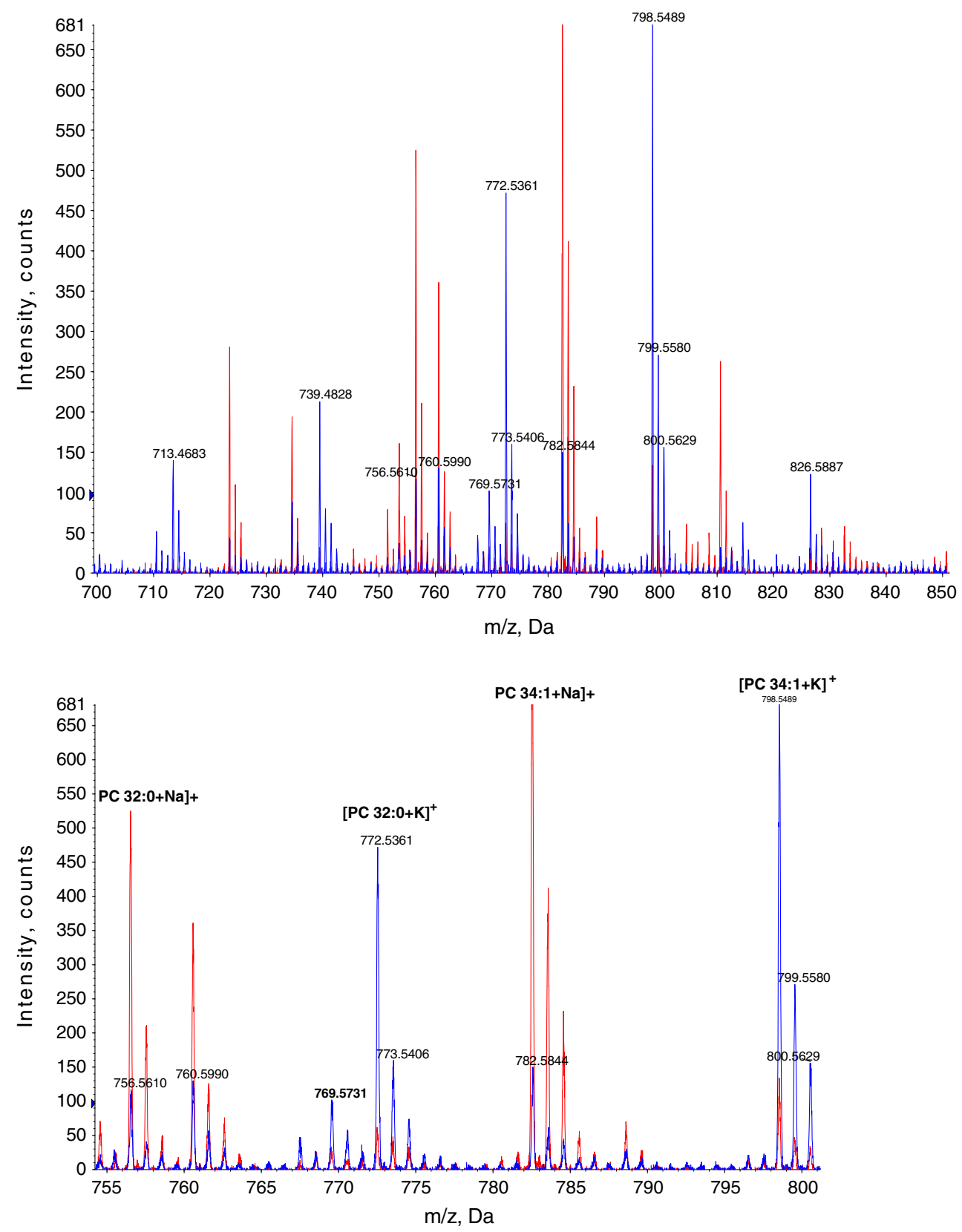

Figure 3. MALDI-MS single point spectra taken from the cerebral cortex area of fresh (blue) and fixed (red) tissue. An enlarged spectral region of interest $(\mathrm{m} / \mathrm{z})$ is presented, ions relating to PC32:0 and PC 34:1 are labeled 
comparing single point spectra obtained from eight different anatomical regions of the brain, for fixed and fresh tissue (data not included). The ion counts for the $[\mathrm{M}+\mathrm{H}]^{+},[\mathrm{M}+\mathrm{Na}]^{+}$, and $[\mathrm{M}+\mathrm{K}]^{+}$ions of PC 32:0, PC 36:1, and SM 18:0 for fixed and fresh were compared. For all species and every location investigated the $[\mathrm{M}+\mathrm{Na}]^{+}$ion is the dominating species for fixed tissue and the $[\mathrm{M}+\mathrm{K}]^{+}$ion was found to be the most abundant ion detected in fresh tissue. The salt content in brain is high, which could be why sodium and potassium adducts are often seen when analyzing brain tissue. The sodium content of the buffered formalin may be responsible for the increase in sodium adduct formation seen. This would explain the difference observed in the ionization pathways for the respective sample preparation methods. A recent report published by Sugiura and co-workers (2009) [76] shows selective ionization pathways are observed with the addition of alkali metals to the matrix solution. This supports the theory of the sodium in the buffered formalin being responsible for the change in ion species seen for the fixed tissue analysis.

\section{Analysis of Formalin Spiked Tissue}

The increase in sodium adduct formation in fixed tissue was further shown in the analysis of formalin spiked fresh tissue samples (top sections, Figure 4). The image of [PC 32:0+Na $]^{+}$ has a much greater ion intensity within the spiked areas compared with the surrounding tissue, as shown by the pixel intensity. This appears to directly correlate with ion suppression of $[\mathrm{PC} 32: 0+\mathrm{K}]^{+}$within the formalin spiked areas, as shown by the change in ion intensity presented in Figure 4 . The difference in the intensity charts next to each image is due to the potassium adduct being predominantly formed in fresh tissue analysis, as previously discussed. Results from this spiking experiment indicate that formalin fixation does not causes

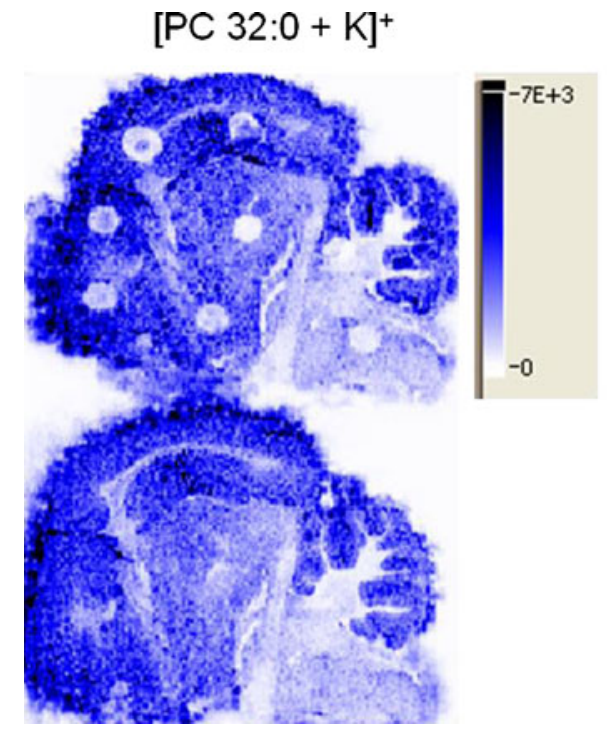

migration or delocalization of imaged lipids. This is illustrated by examining the formalin spike that covers part of the corpus callosum (top left spot of spiked section, $\left.[\mathrm{M}+\mathrm{Na}]^{+}\right)$, an area where PC 32:0 is less abundant. The spike also straddles part of the neighboring cerebral cortex. It is postulated that if analyte migration occurred as a result of formalin spiking (and hence fixation) then lipids from the cerebral cortex may have been detected within the corpus callosum. Low ion counts within the corpus callosum indicate that no migration of PC 32:0 from the cerebral cortex has occurred.

\section{Conclusion}

Lipid species have been successfully ionized directly from formalin fixed tissue without any pre-treatment that could interfere with the distribution of these molecules. High quality molecular lipid images were obtained, showing no signs of delocalization or interference from the formalin itself. Sodium buffers associated with the formalin fixation protocol caused a change in previously reported ionization pathways, and the $[\mathrm{M}$ $+\mathrm{Na}]^{+}$was found to be the most readily detected ion for each lipid species investigated. As the involvement of lipids has now been proven in numerous physiological and pathologic processes, the ability to analyze these species directly from and compare to, histologic specimens could provide a plethora of additional information.

Research presented here indicates that MALDI-MS imaging may be a valuable tool for the investigation of phospholipid species directly from formalin fixed clinical specimens. Further work is needed to identify species detected in fixed tissue, which are not readily detected in fresh sections. A high sodium concentration within the matrix system is known to favorably ionize phosphatidylethanolamine (PE) species, which may also be true for fixed

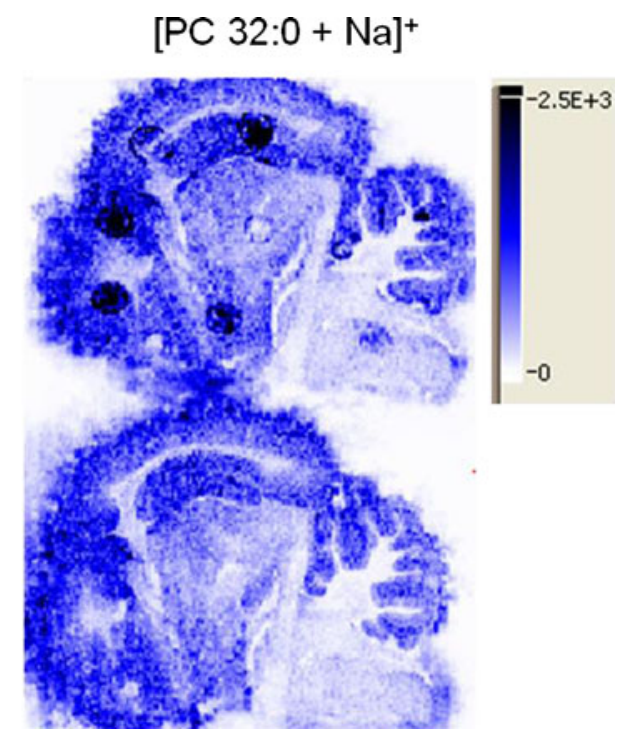

Figure 4. MALDI-MS images of PC 32:0 taken from a sagittal section of formalin spiked tissue, top images, and fresh control section, bottom images. The $[\mathrm{M}+\mathrm{K}]^{+}$species is represented on the left and the $[\mathrm{M}+\mathrm{Na}]^{+}$species on the right 
tissue. Ongoing investigations will focus on ESI-MS/MS analysis of whole brain extracts from fixed and fresh tissue with a view to further profiling the differences afforded by each sample preparation method.

\section{Acknowledgments}

The authors gratefully acknowledge LEAP Technologies for loan of the TM Sprayer and funding for CLC from EPSRC/RSC.

\section{References}

1. Caprioli, R.M., Farmer, T.B., Gile, J.: Molecular imaging of biological samples: localization of peptides and proteins using MALDI-TOF-MS. Anal. Chem. 69(23), 4751-4760 (1997)

2. Ceuppens, R., Dumont, D., Van Brussel, L., Van De Plas, B., Daniels, R., Noben, J.-P., Verhaert, P., Van Der Gucht, E., Robben, J., Clerens, S., Arckens, L.: Direct profiling of myelinated and demyelinated regions in mouse brain by imaging mass spectrometry. Int. J. Mass Spectrom. 260(2/3), 185-194 (2007)

3. Chaurand, P., Cornett, D.S., Caprioli, R.M.: Molecular imaging of thin mammalian tissue sections by mass spectrometry. Curr. Opin. Biotechnol. 17(4), 431-436 (2006)

4. Chaurand, P., Schwartz, S.A., Caprioli, R.M.: Imaging mass spectrometry: a new tool to investigate the spatial organization of peptides and proteins in mammalian tissue sections. Curr. Opin. Chem. Biol. 6(5), 676-681 (2002)

5. Cornett, D.S., Reyzer, M.L., Chaurand, P., Caprioli, R.M.: MALDI imaging mass spectrometry: molecular snapshots of biochemical systems. Nat. Methods 4(10), 828-833 (2007)

6. Crecelius, A.C., Cornett, D.S., Caprioli, R.M., Williams, B., Dawant, B. M., Bodenheimer, B.: Three-dimensional visualization of protein expression in mouse brain structures using imaging mass spectrometry. J. Am. Society for Mass Spectrometry 16(7), 1093-1099 (2005)

7. Fuchsberger, C., Kofler, K., Hammerer, M., Wieder, W., Ongarello, S., Feuerstein, I., Bonn, G.K., Bartsch, G., Pelzer, A.E., Klocker, H.: Imaging of prostate tissue sections by MALDI protein mass spectrometry-TISVIS, a tool for the visual data pocessing. $J$. Urol. 179(Suppl. 1), 389-390 (2008)

8. Reyzer, M.L., Caprioli, R.M.: MALDI-MS-based imaging of small molecules and proteins in tissues. Curr. Opin. Chem. Biol. 11(1), 29-35 (2007)

9. Schwartz, S. A.; Caprioli, R. M.; Károly, V.; András, T.; Akos, V. Molecular Imaging by Mass Spectrometry. In Medical Applications of Mass Spectrometry. Elsevier: Amsterdam, 2008; pp 533-554.

10. Seeley, E.H., Oppenheimer, S.R., Mi, D., Chaurand, P., Caprioli, R.M.: Enhancement of protein sensitivity for MALDI imaging mass spectrometry after chemical treatment of tissue sections. J. Am. Soc. Mass Spectrom. 19(8), 1069-1077 (2008)

11. Stoeckli, M.; Chaurand, P.; Hallahan, E.; Capriopli, R. M. Imaging mass spectrometry: a new technology for the analysis of protein expressions in mammalian tissues. Nat. Med. 7(4), 493-496 (2001)

12. Stoeckli, M.; Knochenmuss, R.; Mccombie, G.; Mueller, D.; Rohner, T.; Staab, D.; Wiederhold, K.; Kheterpal, I.; Ronald, W. MALDI MS Imaging of Amyloid. In Methods in Enzymology. Academic Press: 2006; pp 94-106.

13. Stoeckli, M., Staab, D., Schweitzer, A., Gardiner, J., Seebach, D.: Imaging of a $\beta$-Peptide distribution in whole-body mice sections by MALDI mass spectrometry. J. Am. Soc. Mass Spectrom. 18(11), 1921-1924 (2007)

14. Stoeckli, M., Staab, D., Staufenbiel, M., Wiederhold, K., Signor, L.: Molecular imaging of amyloid $\beta$ peptides in mouse brain sections using mass spectrometry. Analy. Biochem. 311, 33-39 (2002)

15. Bunch, J., Clench, M.R., Richards, D.S.: Determination of pharmaceutical compounds in skin by imaging matrix-assisted laser desorption/ ionization mass spectrometry. Rapid Commun. Mass Spectrom. 18, 3051-3060 (2004)

16. Garrett, T.J., Prieto-Conaway, M.C., Kovtoun, V., Bui, H., Izgarian, N., Stafford, G., Yost, R.A.: Imaging of small molecules in tissue sections with a new intermediate-pressure MALDI linear ion trap mass spectrometer. Int. J. Mass Spectrom. 260(2/3), 166-176 (2007)

17. Hsieh, Y., Casale, R., Fukuda, E., Chen, J., Knemeyer, I., Wingate, J., Morrison, R., Korfmacher, W.: Matrix-assisted laser desorption/ionization imaging mass spectrometry for direct measurement of clozapine in rat brain tissue. Rapid Commun. Mass Spectrom. 20(6), 965-972 (2006)

18. Hsieh, Y.; Korfmacher, W. A. MALDI Imaging Mass Spectrometry for Direct Tissue Analysis of Pharmaceuticals. In Mass Spectrometry in Drug Metabolism and Pharmacokinetics, Ragu, R., Ed.; 2008; pp 359-382.

19. Khatib-Shahidi, S., Andersson, M., Herman, J.L., Gillespie, T.A., Caprioli, R.M.: Direct molecular analysis of whole-body animal tissue sections by imaging MALDI mass spectrometry. Anal. Chem. 78(18), 6448-6456 (2006)

20. Mikawa, S., Suzuki, M., Fujimoto, C., Sato, K.: Imaging of phosphatidylcholines in the adult rat brain using MALDI-TOF MS. Neurosci. Lett. 451(1), 45-49 (2009)

21. Prideaux, B., Atkinson, S.J., Carolan, V.A., Morton, J., Clench, M.R.: Sample preparation and data interpretation procedures for the examination of xenobiotic compounds in skin by indirect imaging MALDI-MS. Int. J. Mass Spectrom. 260(2/3), 243-251 (2007)

22. Puolitaival, S.M., Burnum, K.E., Cornett, D.S., Caprioli, R.M.: Solventfree matrix dry-coating for MALDI imaging of phospholipids. J. Am. Soc. Mass Spectrom. 19(6), 882-886 (2008)

23. Reyzer, M.L., Hsieh, Y., Ng, K., Korfmacher, W.A., Caprioli, R.M.: Direct analysis of drug candidates in tissue by matrix-assisted laser desorption/ionization mass spectrometry. J. Mass Spectrom. 38(10), 1082-1092 (2003)

24. Wang, H.-Y.J., Post, S.N.J.J., Woods, A.S.: A minimalist approach to MALDI imaging of glycerophospholipids and sphingolipids in rat brain sections. Int. J. Mass Spectrom. 278(2/3), 143-149 (2008)

25. Touboul, D., Roy, S., Germain, D.P., Chaminade, P., Brunelle, A., Laprévote, O.: MALDI-TOF and cluster-TOF-SIMS imaging of fabry disease biomarkers. Int. J. Mass Spectrom. 260(2/3), 158-165 (2007)

26. Yanagisawa, K., Shyr, Y., Xu, B.J., Massion, P.P., Larsen, P.H., White, B.C., Roberts, J.R., Edgerton, M., Gonzalez, A., Nadaf, S., Moore, J.H., Caprioli, R.M., Carbone, D.P.: Proteomic patterns of tumor subsets in non-small-cell lung cancer. Lancet 362(9382), 433-439 (2003)

27. Klöppel, G.: Tumour biology and histopathology of neuroendocrine tumors. Best Pract. Res. Clin. Endocrinol. Metab. 21(1), 15-31 (2007)

28. Pileri, S.A., Sabattini, E., Agostinelli, C., Bodega, L., Rossi, M., Zinzani, P.L., Marafioti, T.: Histopathology of B-cell chronic lymphocytic leukemia. Hematol. Oncol. Clin. North Am. 18(4), 807-826 (2004)

29. Allred, D.C., Moshin, S.: The assessment of hormone receptors in breast cancer by immunohistochemistry. Seminars in Breast Disease: Radiologic, Pathologic and Surgical Considerations 8(2), 57-61 (2005)

30. Giordano, G.: Value of immunohistochemistry in uterine pathology: common and rare diagnostic dilemmas. Pathol. Res. Pract. 205(10), 663-676 (2009)

31. Benabdellah, F., Yu, H., Brunelle, A., Laprévote, O., De La Porte, S.: MALDI reveals membrane lipid profile reversion in MDX mice. Neurobiol. Dis. 36(2), 252-258 (2009)

32. Deininger, S.R.-O., Ebert, M.P., Fütterer, A., Gerhard, M., Röcken, C.: MALDI imaging combined with hierarchical clustering as a new tool for the interpretation of complex human cancers. J. Proteome Res. 7 (12), 5230-5236 (2008)

33. Rohner, T.C., Staab, D., Stoeckli, M.: MALDI mass spectrometric imaging of biological tissue sections. Mech. Aging Dev. 126(1), $177-185$ (2005)

34. Shimma, S., Sugiura, Y., Hayasaka, T., Hoshikawa, Y., Noda, T., Setou, M.: MALDI-based imaging mass spectrometry revealed abnormal distribution of phospholipids in colon cancer liver metastasis. J. Chromatogr. B 855(1), 98-103 (2007)

35. Buesa, R.J.: Histology without formalin? Ann. Diagnost. Pathol. 12(6), 387-396 (2008)

36. Moreau, A., Le Neel, T., Joubert, M., Truchaud, A., Laboisse, C.: Approach to automation in immunohistochemistry. Clin. Chim. Acta 278(2), 177-184 (1998)

37. Shi, S.-R., Cote, R.J., Taylor, C.R.: Antigen retrieval immunohistochemistry: past, present, and future. J. Histochem. Cytochem. 45(3), 327-344 (1997)

38. Shi, S.-R., Liu, C., Balgley, B.M., Lee, C., Taylor, C.R.: Protein extraction from formalin-fixed, paraffin-embedded tissue sections: 
quality evaluation by mass spectrometry. J. Histochem. Cytochem. $\mathbf{5 4}$ (6), 739-743 (2006)

39. Werner, M., Chott, A., Fabiano, A., Battifora, H.: Effect of formalin tissue fixation and processing on immunohistochemistry. Am. J. Surg. Pathol. 24(7), 1016-1019 (2000)

40. Ramos-Vara, J.A.: Technical aspects of immunohistochemistry. Veterinary Pathol. Online 42(4), 405-426 (2005)

41. Lemaire, R., Desmons, A., Tabet, J.C., Day, R., Salzet, M., Fournier, I.: Direct analysis and MALDI imaging of formalin-fixed, paraffinembedded tissue sections. J. Proteome Res. 6(4), 1295-1305 (2007)

42. Stauber, J., Lemaire, R., Franck, J., Bonnel, D., Croix, D., Day, R., Wisztorski, M., Fournier, I., Salzet, M.: MALDI imaging of formalinfixed paraffin-embedded tissues: application to model animals of Parkinson disease for biomarker hunting. J. Proteome Res. 7(3), 969-978 (2008)

43. Aoki, Y., Toyama, A., Shimada, T., Sugita, T., Aoki, C., Umino, Y., Suzuki, A., Aoki, D., Daigo, Y., Nakamura, Y., Sat, T.-A.: A novel method for analyzing formalin-fixed paraffin embedded (FFPE) tissue sections by mass spectrometry imaging. Proc. Japan Acad. Series B $\mathbf{8 3}$ (7), 205-214 (2007)

44. Walch, A.; Rauser, S.; Deininger, S.-O.; Hofler, H. MALDI imaging mass spectrometry for direct tissue analysis: a new frontier for molecular histology. J. Histochem. Cell Biol. 130(3), 421-434 (2008)

45. Chaurand, P., Schwartz, S.A., Billheimer, D., Xu, B.J., Crecelius, A., Caprioli, R.M.: Integrating histology and imaging mass spectrometry. Anal. Chem. 76(4), 1145-1155 (2004)

46. Astigarraga, E., Barreda-Goìez, G., Lombardero, L., Fresnedo, O., Castanìfo, F., Giralt, M.A.T., Ochoa, B., RodriìGuez-Puertas, R., FernaiNdez, J.A.: Profiling and imaging of lipids on brain and liver tissue by matrix-assisted laser desorption/ionization mass spectrometry using 2-mercaptobenzothiazole as a matrix. Anal. Chem. 80(23), 9105-9114 (2008)

47. Baluya, D.L., Garrett, T.J., Yost, R.A.: Automated MALDI matrix deposition method with inkjet printing for imaging mass spectrometry. Anal. Chem. 79(17), 6862-6867 (2007)

48. Burnum, K.E., Cornett, D.S., Puolitaival, S.M., Milne, S.B., Myers, D. S., Tranguch, S., Brown, H.A., Dey, S.K., Caprioli, R.M.: Spatial and temporal alterations of phospholipids determined by mass spectrometry during mouse embryo implantation. J. Lipid Res. 50(11), 2290-2298 (2009)

49. Chan, K., Lanthier, P., Liu, X., Sandhu, J.K., Stanimirovic, D., Li, J.: MALDI mass spectrometry imaging of gangliosides in mouse brain using ionic liquid matrix. Anal. Chim. Acta 639(1/2), 57-61 (2009)

50. Fujiwaki, T., Tasaka, M., Takahashi, N., Kobayashi, H., Murakami, Y., Shimada, T., Yamaguchi, S.: Quantitative evaluation of sphingolipids using delayed extraction matrix-assisted laser desorption ionization time-of-flight mass spectrometry with sphingosylphosphorylcholine as an internal standard: practical application to cardiac valves from a patient with fabry disease. J. Chromatogr. B 832(1), 97-102 (2006)

51. Hankin, J.A., Barkley, R.M., Murphy, R.C.: Sublimation as a method of matrix application for mass spectrometric imaging. J. Am. Soc. Mass Spectrom. 18(9), 1646-1652 (2007)

52. Ivanova, P.T., Milne, S.B., Myers, D.S., Brown, H.A.: Lipidomics: a mass spectrometry based systems level analysis of cellular lipids. Curr. Opin. Chem. Biol. 13(5/6), 526-531 (2009)

53. Jackson, S.N., Wang, H.-Y.J., Woods, A.S.: In situ structural characterization of phosphatidylcholines in brain tissue using MALDI-MS/MS. J. Am. Soc. Mass Spectrom. 16(12), 2052-2056 (2005)

54. Jackson, S.N., Wang, H.-Y.J., Woods, A.S.: Direct profiling of lipid distribution in brain tissue using MALDI-TOFMS. Anal. Chem. 77(14), 4523-4527 (2005)

55. Jackson, S.N., Woods, A.S.: Direct profiling of tissue lipids by MALDI-TOFMS. J. Chromatogr. B 877(26), 2822-2829 (2009)

56. Jaskolla, T., Fuchs, B., Karas, M., Schiller, J.: The new matrix 4chloro- $\leftrightarrow$-cyanocinnamic acid allows the detection of phosphatidylethanolamine chloramines by MALDI-TOF mass spectrometry. $J$. Am. Soc. Mass Spectrom. 20(5), 867-874 (2009)

57. Landgraf, R.R., Prieto Conaway, M.C., Garrett, T.J., Stacpoole, P.W., Yost, R.A.: Imaging of lipids in spinal cord using intermediate pressure matrix-assisted laser desorption-linear ion trap/orbitrap MS. Anal. Chem. 81(20), 8488-8495 (2009)

58. Ma, X., Liu, G., Wang, S., Chen, Z., Lai, M., Liu, Z., Yang, J. Evaluation of sphingolipids changes in brain tissues of rats with pentylenetetrazol-induced kindled seizures using MALDI-TOF-MS. $J$. Chromatogr. B 859(2), 170-177 (2007)

59. Schiller, J., Sub, R., Arnhold, J., Fuchs, B., Lebig, J., Muller, M., Petkovic, M., Spalteholze, H., Zscornig, O., Arnold, K.: Matrix-assisted laser desorption and ionization time-of-flight (MALDI-TOF) mass spectrometry in lipid and phospholipids research. Prog. Lipid Res. 43, 449-488 (2004)

60. Cowart, L.A.: Sphingolipids: players in the pathology of metabolic disease. Trends Endocrin. Metab. 20(1), 34-42 (2009)

61. Florent-Béchard, S., Desbène, C., Garcia, P., Allouche, A., Youssef, I., Escanyé, M.-C., Koziel, V., Hanse, M., Malaplate-Armand, C., Stenger, C., Kriem, B., Yen-Potin, F.T., Olivier, J.L., Pillot, T., Oster, T.: The essential role of lipids in Alzheimer's disease. Biochimie 91(6), 804-809 (2009)

62. Fujiwaki, T., Yamaguchi, S., Tasaka, M., Takayanagi, M., Isobe, M., Taketomi, T.: Evaluation of sphingolipids in vitreous bodies from a patient with Gaucher disease, using delayed extraction matrix-assisted laser desorption ionization time-of-flight mass spectrometry. $J$. Chromatogr. B 806(1), 47-51 (2004)

63. Huwiler, A., Pfeilschifter, J.: Lipids as targets for novel antiinflammatory therapies. Pharmacol. Therapeut. 124(1), 96-112 (2009)

64. Mcmillin, J.B., Dowhan, W.: Cardiolipin and apoptosis. Biochim. Biophys. Acta (BBA)-Mol. Cell Biol. Lipids 1585(2/3), 97-107 (2002)

65. Piomelli, D.: The challenge of brain lipidomics. Prostaglandins Other Lipid Mediat. 77(1/4), 23-34 (2005)

66. Stachowska, E., Gutowska, I., Dolegowska, B., Chlubek, D., Bober, J., Rac, M., Gutowski, P., Szumilowicz, H., Turowski, R.: Exchange of unsaturated fatty acids between adipose tissue and atherosclerotic plaque studied with artificial neural networks. Prostaglandins Leukotrienes Essential Fatty Acids 70(1), 59-66 (2004)

67. Watson, A.D.: Thematic review series: systems biology approaches to metabolic and cardiovascular disorders. Lipidomics: A global approach to lipid analysis in biological systems. J. Lipid Res. 47(10), 2101-2111 (2006)

68. Wei, S., Ong, W.Y., Thwin, M.M., Fong, C.W., Farooqui, A.A., Gopalakrishnakone, P., Hong, W.: Group IIA secretory phospholipase A2 stimulates exocytosis and neurotransmitter release in pheochromocytoma-12 cells and cultured rat hippocampal neurons. Neuroscience 121(4), 891-898 (2003)

69. Zhu, C., Hu, P., Liang, Q.-L., Wang, Y.-M., Luo, G.-A.: Recent advances in lipidomics. Chin. J. Anal. Chem. 37(9), 1390-1396 (2009)

70. Rujol, M., Estrada, R., Yappert, M.C.: In situ MALDI-TOF MS regional analysis of neutral phospholipid in lens tissue. Anal. Chem. 76, 1657-1663 (2004)

71. Chen, Y., Allegood, J., Liu, Y., Wang, E., Cachon-Gonzalez, B., Cox, T.M., Merrill, A.H., Sullards, M.C.: Imaging MALDI mass spectrometry using an oscillating capillary nebulizer matrix coating system and its application to analysis of lipids in brain from a mouse model of Tayâ^`Sachs/Sandhoff disease. Anal. Chem. 80(8), 2780-2788 (2008)

72. Jackson, S.N., Wang, H.-Y.J., Woods, A.S., Ugarov, M., Egan, T., Schultz, J.A.: Direct tissue analysis of phospholipids in rat brain using MALDI-TOFMS and MALDI-ion mobility-TOFMS. J. Am. Soc. Mass Spectrom. 16(2), 133-138 (2005)

73. Murphy, R.C., Hankin, J.A., Barkley, R.M.: Imaging of lipid species by MALDI mass spectrometry. J. Lipid Res. 50(Suppl), S317-S322 (2009)

74. Jackson, S.N., Ugarov, M., Post, J.D., Egan, T., Langlais, D., Schultz, J. A., Woods, A.S.: study of phospholipids by ion mobility TOFMS. $J$. Am. Soc. Mass Spectrom. 19(11), 1655-1662 (2008)

75. Jurchen, J.C., Rubakhin, S.S., Sweedler, J.V.: MALDI-MS imaging of features smaller than the size of the laser beam. J. Am. Soc. Mass Spectrom. 16(10), 1654-1659 (2005)

76. Sugiura, Y., Konishi, Y., Zaima, N., Kajihara, S., Nakanishi, H., Taguchi, R., Setou, M.: Visualization of the cell-selective distribution of PUFA-containing phosphatidylcholines in mouse brain by imaging mass spectrometry. J. Lipid Res. 50(9), 1776-1788 (2009) 